\title{
Magnitude of iodine deficiency disorder and associated factors in Dawro zone, Southwest Ethiopia; the hidden hunger: a cross-sectional study
}

Agize Asfaw ${ }^{1 *}$ and Tefera Belachew ${ }^{2}$

\begin{abstract}
Background: lodine deficiency disorder (IDD) is continued to be a major public health problem in Ethiopia. The problem is worse but the data is scarce in some pocket areas of the country. This study was aimed to assess the magnitude of IDD and associated factors in southwest Ethiopia by using different biochemical and clinical indicators.

Methods: Both community and school based cross- sectional study was conducted on school age children (6-12 years) from March 1 to 24, 2017. Simple random and systematic sampling techniques were applied to select districts and eligible children respectively. Household data was collected from children's primary care takers by using structured questionnaire. A trained surgeon examined all children $(n=652)$ for goiter. Urine sample was collected from $20 \%$ of children $(n=130)$.

Results: A total of 652 school children were participated in the study. Total goiter rate and median urinary iodine concentration (UIC) was $54.8 \%$ and $96.12 \mu \mathrm{g} / \mathrm{l}$ respectively. In multivariable logistic regression analyses student's age was significantly $(P<0$ 05) associated with both goiter and median UIC. However; sex of students and family income were significantly $(P<0.001)$ associated with goiter and cassava consumption was significantly $(P<0.001)$ associated with UIC.

Conclusion: As indicated by the median UIC, there was mild iodine deficiency in this study community. However; chronic iodine deficiency was still a severe public health problem (high goiter prevalence). In addition, there was low concentration of iodine in the salt and increased cassava cultivation and consumption indicating the potential risk in the area. Therefore, it is necessary to intensify IDD elimination activities along with teaching communities on techniques of cassava processing for household consumption.
\end{abstract}

Trial registration: PACTR201809544276357. Retrospectively registered on 14, Sept 2018.

Keywords: Iodine deficiency disorder, Urinary iodine excretion, Goiter, Dawro, Ethiopia

\footnotetext{
* Correspondence: agisha238@gmail.com

'Department of Public Health, College of Medicine and Health Sciences, Wolkite University, P.O.Box: 07, Gubre, Ethiopia

Full list of author information is available at the end of the article
}

(c) The Author(s). 2020 Open Access This article is licensed under a Creative Commons Attribution 4.0 International License, which permits use, sharing, adaptation, distribution and reproduction in any medium or format, as long as you give appropriate credit to the original author(s) and the source, provide a link to the Creative Commons licence, and indicate if changes were made. The images or other third party material in this article are included in the article's Creative Commons licence, unless indicated otherwise in a credit line to the material. If material is not included in the article's Creative Commons licence and your intended use is not permitted by statutory regulation or exceeds the permitted use, you will need to obtain permission directly from the copyright holder. To view a copy of this licence, visit http://creativecommons.org/licenses/by/4.0/ The Creative Commons Public Domain Dedication waiver (http://creativecommons.org/publicdomain/zero/1.0/) applies to the data made available in this article, unless otherwise stated in a credit line to the data. 


\section{Background}

Iodine is a trace element sparsely distributed over the surface of the earth. It is essential for the synthesis of the thyroid hormones, thyroxin $\left(\mathrm{T}_{4}\right)$ and triiodothyronine $\left(\mathrm{T}_{3}\right)$, which are necessary for human growth and development. According to world health organization (WHO), United Nations children's fund (UNICEF) and iodine global network (IGN), the recommended daily intake of iodine is $120 \mu \mathrm{g} /$ day for school children (6-12 years) and $150 \mu \mathrm{g} /$ day for adults. This means, on average the total quantity of iodine needed for an individual over a lifetime is only about one tea spoonful $[1,2]$.

Failure to have such small but very essential element can lead to several important consequences collectively known as iodine deficiency disorders (IDD). The spectrum of IDD includes impaired mental function, delayed physical development, goiter, hypothyroidism, cretinism, reproductive failure and increased infant mortality [3].

Among micronutrient deficiencies, iodine deficiency (ID) deserves highest priority, because it is the world's single most significant cause of preventable brain damage and mental retardation in children $[4,5]$. Despite the availability of a safe and simple solution for its elimination, iodized salt, it continued to be one of the main public health challenges in the world. The problem is worse in developing countries especially among population living in highland areas [6-8].

\section{Factors associated with iodine deficiency}

Even though, the main reason for IDD is a low dietary intake of iodine [9], several other factors also play significant role. Living in highland areas where the soil has low iodine content as a result of loss of iodine due to repeated leaching effects of snow, water, over-grazing by livestock, tree-cutting for firewood, and heavy rainfall, consumption of goitrogenic foods like cassava, millet, soya bean, kale, cabbage which interferes with the metabolism of iodine and other nutritional deficiencies including vitamin $\mathrm{A}$, protein energy malnutrition and iron deficiency anemia, all contribute to the occurrence of IDD [10, 11].

Generally, factors that contribute to the occurrence of IDD are complex including environmental, social, economic, educational and service related as indicated by previous studies [12-14].

Global iodine nutrition status and rationale for this study Global studies conducted to assess iodine nutrition status over the past several decades had shown improved iodine nutrition status. According to these studies, in 1993 about 113 countries were iodine deficient. In 2003, after a decade, the number of iodine deficient countries declined to 54 [15]. After another decade, in 2013, this number decreased to 30 and currently in 2017 only 19 countries remain iodine-deficient [16, 17]. However; there was a sharp regional and urban/rural difference which still needs great global effort to combat IDD. There are great differences even in countries located within the same continent $[18,19]$.

Ethiopia is known for its mountainous topography and at risk of IDD. As indicated by national community based survey of 2007, the weighted total goitre prevalence was $35.8 \%$ and the median UIC level was less than $100 \mu \mathrm{g} / \mathrm{l}$ in all regions of the country [20]. Even though, IGN by its global scorecard of iodine nutrition of 2017 categorized the country as "adequate" in iodine intake at national level [21], several recently conducted subnational studies revealed that the country is iodine deficient [11, 22-26]. In addition the availability of adequately iodized salt at household level was low [27].

In the current study area there is no data about the iodine status of the population, but there are several indicators for the existence of risk of IDD (the mountainous nature, high rain fall for most seasons of the year and availability and consumption of goitrogenic foods). Therefore, the major objective of this study was to assess the magnitude and predictors of IDD in Dawro zone, southwest Ethiopia and provide data for evidence based public health intervention.

\section{Methods}

\section{Description of the study area}

This study was conducted in Dawro zone, southwest Ethiopia. The zone is one of the 14 zones found in south nation nationalities and people's region (SNNPR) with a total land area of about $4437 \mathrm{~km}^{2}$. The capital of the zone is Tarcha, which is found $500 \mathrm{Km}$ from Addis Ababa, the national capital in the south west direction. The total population of the zone was 702,517 in 2016 of which $50.9 \%$ are males and the remaining $49.1 \%$ are females. It has 3 different agro-ecological zones; high land with altitude over 2300masl (29\%), middle land between 1500 to 2300 masl (41\%) and low land below 1500 masl (30\%). The annual temperature and rainfall ranges from 15.1 $370 \mathrm{c}$ and $1800-2500 \mathrm{~mm}$ respectively $[28,29]$.

\section{Study design}

Both community and school based cross- sectional study design was conducted from March 1 to 24, 2017. The study focused on school age children (SAC) aged 6-12 years. According to WHO/ UNICEF/IGN, these groups are a useful target for IDD surveillance because of their combined high vulnerability, easy access, applicability to a variety of surveillance activities and relative representativeness of the study population $[2,30]$. 


\section{Source and study population}

The source populations were all primary school children (6-12 years) in Dawro zone and the study populations were the same children from selected primary schools.

\section{Eligibility criteria}

Inclusion

SAC (6-12 years) of both sexes from selected schools.

\section{Exclusion}

Children whose parents/guardians refuse to give consent and those who are outside the age range were excluded.

\section{Sampling technique}

Two out of the five districts were selected by simple random sampling (SRS) and the town administration was included. Each district was stratified in to two agro-ecological zones based on their altitudes, highland $(\geq 1500 \mathrm{~m}$ above sea level) and lowland ( $<1500 \mathrm{~m}$ above sea level). For the town administration no need of stratification as it is the known low land. The list of primary schools (sampling frame) was obtained from district education offices and the town administration bureau. Again SRS was applied to select a primary school from each stratum and the town. Then, sample was allocated proportional to the number of students of each school. Eligible children in these schools were randomly selected and given an ID number. Finally, the following activities were carried out with the children and their mother/primary care taker:

A. Clinical examination for goiter: A surgeon from Tarcha general hospital trained for 3 days on thyroid gland examination and grading. The training was given by another surgeon working in department of surgery with special training on endocrinology. The trained surgeon examined all selected children by inspection and palpation. The goiter grading was performed by using WHO classification [2] as:

- Grade 0- Neither visible nor palpable in normal position (no neck swelling or normal)

- Grade 1 - Thyroid swelling which is not seen but palpable in normal position

- Grade 2 - Thyroid swelling which is both visible and palpable in normal position

B. Urine Samples: Casual urine samples of about $5 \mathrm{ml}$ [30] was collected from $20 \%(n=130)$ of children by using labeled plastic bottles with screw cap and put in an ice-packed cool box. The collected urine was transported to Tarcha general hospital laboratory for storage in a refrigerator at $-40 \mathrm{oc}$ until it was transported to Ethiopian public health institute for analysis using modified Sandell-Kolthoff reaction. The result of UIC was expressed as micrograms of iodine per $100 \mathrm{ml}$ of urine. Finally, the iodine status of children was classified by using WHO/UNICEF/ IGN recommended cut-off points for UIC [2, 31, 32].

C. Salt samples: A sub-sample of $230(\sim 35 \%)$ households were selected from the main sample of 652 . During data collection, interviewers asked every third households to provide two teaspoon of salt used for cooking. The collected sample was labeled with a code and submitted to principal investigator (PI). Then the sample was tested by trained laboratory technologist using iodine rapid test kit (MBI Kits International) for its iodine content. The iodine concentration was recorded as $0,<15$, or $\geq 15$ PPM $[2,31,32]$.

D. Household interview: Data collectors conducted household interview with the children's mother or primary care taker by using pre-tested structured questionnaire. The questionnaire included sociodemographic, behavioral, nutritional and other factors that can possibly be associated with IDD.

\section{Operational definitions}

- Goiter Prevalence:- Grade 1 and Grade 2 goiter collectively

- Iodine content of salt samples: 0 ppm (no iodine in the salt), $<15 \mathrm{ppm}$ (inadequately iodized salt) and $\geq 15 \mathrm{ppm}$ (adequately iodized salt).

\section{Data processing and analysis}

Data was re-checked for completeness and consistency after fieldwork. Then, coded on pre-arranged coding sheet by the PI and doubly entered into Epi Info version 3.5.3 and transferred to SPSS version 21 software packages. Before analysis it was cleaned and checked for consistency and possible outliers. Any incomplete or invalid data, outliers or missing values were evaluated against hard copy. Tables, graphs and figures were used to show frequencies and main findings.

A binary logistic regression model was fitted to identify factors associated with UIC and goiter. Variables with a $p$-value $\leq 0.2$ in the bivariable analysis and those which frequently showed significant association with UIC and goiter in the previous studies were fitted into the multivariable logistic regression analysis and backward LR method was employed to control confounding. Both Crude Odds Ratio (COR) and Adjusted Odds Ratio (AOR) with the corresponding 95\% Confidence Interval (CI) were calculated to show the strength of association. Variables with a $p$-value of $\leq 0.05$ were considered as statistically significant. 


\section{Data quality assurance}

To ensure data quality, structured questionnaire was developed first in English then translated to Amharic by language expert and back to English to maintain its consistency. Five percent of it was pre-tested. Data collectors were trained for 3 days. Data was checked and cleared every day for completeness and consistency during the fieldwork. Close monitoring and supervision of data collectors was carried out to maintain data quality. Goiter examination was carried out by experienced surgeon from Gessa hospital. Twenty children (3\% of the sample) randomly selected from the children examined for goiter and taken to Tarcha general hospital surgical department for re-examination by senior surgeon who was blinded about the result of the previous surgeon. When the result of both surgeons cross-checked, there was no misdiagnosis, but only $5 \%$ misclassification was observed. That is one child, among the 20, was classified as having 'grade 1 goiter' by first surgeon but the second surgeon classified him as having 'grade 2 goiter'.

\section{Results}

Socio-demographic characteristics of children

A total of 652 SAC (6-12 years) from six primary schools were included in the study. Two hundred ninety seven (45.6\%) were male and 355 (54.4\%) were female. The mean age \pm SD of participant children was $9.24 \pm$ 1.29 years.

\section{Goiter prevalence in children}

All 652 SAC were examined for goiter. The goiter prevalence (Grade 1+Grade 2) was 54.6\%, of which 278
(78.1\%) was grade 1 and the rest 78 (21.9\%) was grade 2 goiter. Grade 0 means there is no visible or palpable swelling on the neck (normal). As indicated in Table 4, the prevalence of goiter increased with increasing age and feminine sex.

\section{Urinary iodine concentration in children}

The median UIC was $96.12 \mu \mathrm{g} / \mathrm{l}$ which is close to the WHO recommended cut-off $100 \mu \mathrm{g} / \mathrm{l}$. When we observe the UIC values for the individual children, 66 (50.8\%) of the children had UIC value $<100 \mu \mathrm{g} / \mathrm{l}$ (Fig. 1).

\section{Socio-demographic and economic characteristics of parents}

The majority 642 (98.5\%) of the respondents were female of reproductive age group. The mean age \pm SD of participants was $29.9 \pm 8.0$ years and ranged from 15 to 49 years. Four hundred and sixteen $(63.8 \%)$ of households had family size $\leq 5$ and the average was 4.92 with SD of 1.92. More than half of the households (52.6\%) gain less than 500 Ethiopian birr per month. Almost all participants 639 (98.0\%) were Dawro by ethnicity, majority $489(75.0 \%)$ were protestant followed by Orthodox 121 (18.6\%) Christians. Most of them were married 522 (80.1\%) and housewives in occupation 463 (71.0\%). Three hundred eighty five (59\%) had no formal education, whereas only 47 (7.2\%) had college and above level in education (Table 1).

\section{lodine content of salt samples}

The iodine content of salt sample $(n=230)$ was assessed at household level. According to the result, almost two-

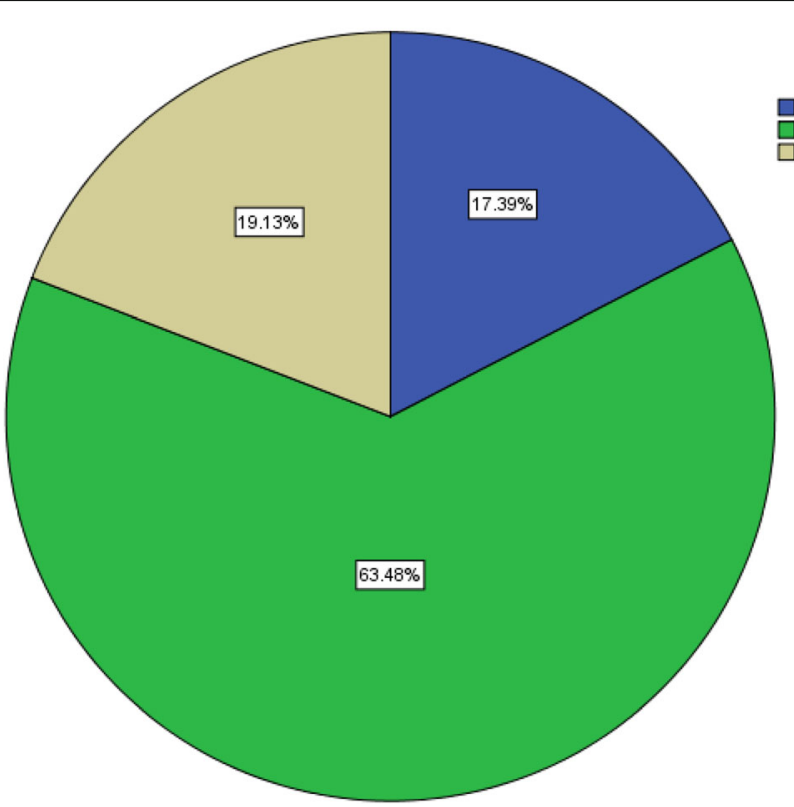

lodine content of household salt sample

$\square$ No iodine in the salt lodine content $<15 \mathrm{PPm}$ lodine content $>=15 \mathrm{PPm}$

Fig. 1 The iodine content of household salt sample, Dawro zone, southwest Ethiopia, 2017 
Table 1 Socio-demographic and economic characteristics of the study participants in Dawro zone, southwest Ethiopia, 2017, $(n=652)$

\begin{tabular}{lll}
\hline Character & Frequency & Perce \\
\hline $\begin{array}{l}\text { Family Size } \\
\leq 5\end{array}$ & 416 & \\
$\quad>5$ & 236 & 36.8 \\
Age of the responded parent & & \\
$15-24$ & 162 & 24.8 \\
$25-34$ & 311 & 47.7 \\
$35-44$ & 127 & 19.5 \\
$45+$ & 52 & 8.0
\end{tabular}

Age of the children

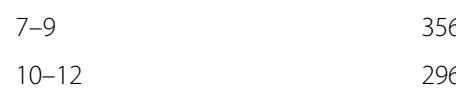

Sex of the responded parent

$\begin{array}{ll}\text { Female } & 642 \\ \text { Male } & 10\end{array}$

Sex of the children

Female

Male

Ethnicity

Dawro

Others $^{\mathrm{a}}$

Educational status of the responded parent Can't read and write 287

Can read and write

Grade 1-8

Grade 9-12

College and above

Occupation

House wife

Others ${ }^{c}$

Marital status of the responded parent

Single

Married

Religion of the responded parent

Orthodox

Protestant

Catholic

Muslim

489

Geographic location

Highland (Dega)

Lowland (Kolla)

Monthly family income (in Eth.Birr)

$<500$
Table 1 Socio-demographic and economic characteristics of the study participants in Dawro zone, southwest Ethiopia, 2017, $(n=652)$ (Continued)

\begin{tabular}{cll}
\hline Character & Frequency & Percent \\
\hline $500-1500$ & 235 & 36.0 \\
$>1500$ & 74 & 11.4 \\
\hline
\end{tabular}

${ }^{\mathrm{a} K o n t a,}$ Wolaita, Amhara ${ }^{\mathrm{b}}$ Divorced, widowed, separately living ${ }^{\mathrm{C}}$ Farmer,

Merchant, Government employee, Student and Daily laborer

third, 146 (63.5\%) of households were using inadequately iodized salt (<15 ppm), $40(17.4 \%)$ were using salt that had no iodine at all $(0 \mathrm{ppm})$ and only $44(19.1 \%)$ of the households were using adequately iodized salt (> $15 \mathrm{ppm})$.

\section{Use of Goitrogenic food}

The result from household questionnaire had shown that goitrogenic foods like Cassava, Cabbage, Kale, Sorghum, were consumed with different frequency in a week. On the other hand consumption of iodine sources, especially sea foods like fish were scarce, but staples such as egg, milk and milk products were common (Table 2).

\section{Prevalence of IDD in the study area}

According to WHO, UNICEF and IGN, the presence and severity of ID in the general population can be indicated by its appearance among representative sample of SAC. In this study, the median UIC in SAC was $96.12 \mu \mathrm{g} / \mathrm{l}$, which is close to the WHO recommended cut-off $100 \mu \mathrm{g} / \mathrm{l}$ reflecting mild iodine deficiency in this study population.

\section{Factors associated with urinary iodine concentration}

In the bivariate logistic regression analysis, age and sex of children, family size and cassava consumption were significantly associated with UIC level. Then all variables with $P \leq 0.20$ and those which frequently showed significant association with UIC in the previous studies [11, $13,19,24]$ were entered in to multivariable logistic regression analyses. Student's age, family size, geographic location and cassava consumption were significantly associated with UIC (Table 3).

\section{Factors associated with goiter}

As done for the UIC level, the same analyses were carried out for goiter. According to the result, age and sex of children, family education and monthly income were significantly associated with goiter in the bivariate logistic regression analysis. However, in multivariable logistic regression analyses only age and sex of children and family monthly income were significant and remained the independent predictors of goiter (Table 4). 
Table 2 Selected types of food used by the respondent and her/his family with its frequency of consumption per week in Dawro zone, southwest Ethiopia, 2017, $(n=652)$

\begin{tabular}{|c|c|c|c|c|c|}
\hline \multirow[t]{2}{*}{ Food type } & \multicolumn{5}{|c|}{ Frequency of consumption per week } \\
\hline & $\begin{array}{l}\text { Every day } \\
\text { No }(\%)\end{array}$ & $\begin{array}{l}\text { 4-6x/week } \\
\text { No (\%) }\end{array}$ & $\begin{array}{l}\text { 1-3x/week } \\
\text { No (\%) }\end{array}$ & $\begin{array}{l}\text { Sometimes } \\
\text { No (\%) }\end{array}$ & $\begin{array}{l}\text { Never } \\
\text { No (\%) }\end{array}$ \\
\hline Cassava & $0(0.0)$ & $17(2.6)$ & $114(17.5)$ & $232(35.6)$ & $289(44.3)$ \\
\hline Cabbage & $0(0.0)$ & $33(5.1)$ & $336(51.5)$ & $222(34.0)$ & $61(9.4)$ \\
\hline Kale & $155(23.8)$ & $205(31.4)$ & $250(38.3)$ & $33(5.1)$ & $9(1.4)$ \\
\hline Sorghum & $3(0.5)$ & $62(9.5)$ & $162(24.8)$ & $228(35.0)$ & $197(30.2)$ \\
\hline Sweet potato & $26(4.0)$ & $79(12.1)$ & $217(33.3)$ & $243(37.3)$ & $87(13.3)$ \\
\hline Soya bean & $0(0.0)$ & $4(0.6)$ & $100(15.3)$ & $176(27.0)$ & $372(57.1)$ \\
\hline Fish & $0(0.0)$ & $0(0.0)$ & $49(7.5)$ & $60(9.2)$ & $543(83.3)$ \\
\hline Egg & $5(0.8)$ & $34(5.2)$ & $301(46.2)$ & $287(44.0)$ & $25(3.8)$ \\
\hline Milk \& milk products & $33(5.1)$ & $55(8.4)$ & $327(50.2)$ & $226(34.7)$ & $11(1.7)$ \\
\hline
\end{tabular}

Bolded food items considered as containing goitrogenic substances (risk)

Non-bolded food items considered as sources of iodine (Protective)

Table 3 Factors associated with UIC level at primary school children in Dawro zone, southwest Ethiopia, 2017, $(n=130)$

\begin{tabular}{|c|c|c|c|c|}
\hline \multirow{2}{*}{$\begin{array}{l}\text { Variables with } \\
\text { Category }\end{array}$} & \multicolumn{2}{|l|}{ UIC ( $\mu \mathrm{g} / \mathrm{I})$} & \multirow{2}{*}{$\begin{array}{l}\text { Crude OR } \\
(95 \% \mathrm{Cl})\end{array}$} & \multirow{2}{*}{$\begin{array}{l}\text { Adjusted OR } \\
(95 \% \mathrm{Cl})\end{array}$} \\
\hline & Sufficient $^{b}$ & Insufficient $^{c}$ & & \\
\hline \multicolumn{5}{|l|}{ Age of the student } \\
\hline $7-9$ years & 18 & 37 & 1 & 1 \\
\hline $10-12$ years & 48 & 27 & $3.65(1.75,7.62)^{* *}$ & $3.57(1.33,9.62)^{*}$ \\
\hline \multicolumn{5}{|l|}{ Sex of the student } \\
\hline Male & 19 & 24 & 1 & 1 \\
\hline Female & 40 & 47 & $2.64(1.24,5.65)^{*}$ & $2.71(0.89,8.26)$ \\
\hline \multicolumn{5}{|l|}{ Family size } \\
\hline$<=5$ & 50 & 63 & 1 & 1 \\
\hline$>5$ & 14 & 3 & $0.17(0.05,0.63)^{*}$ & $0.14(0.02,0.77)^{*}$ \\
\hline \multicolumn{5}{|l|}{ Family education } \\
\hline Informal education & 26 & 25 & 1 & a \\
\hline Formal education & 38 & 41 & $1.12(0.56,2.27)$ & a \\
\hline \multicolumn{5}{|l|}{ Geographic location } \\
\hline Lowland & 37 & 39 & 1 & 1 \\
\hline Highland & 27 & 27 & $0.95(0.47,1.91)$ & $0.22(0.06,0.75)^{*}$ \\
\hline \multicolumn{5}{|l|}{ Duration of stay } \\
\hline$<=1$ year & 2 & 3 & 1 & a \\
\hline$>1$ year & 62 & 63 & $0.68(0.11,4.19)$ & a \\
\hline \multicolumn{5}{|l|}{ Family income/month } \\
\hline$<500$ Eth. Birr & 32 & 36 & 1 & \\
\hline 500-1500 Eth. Birr & 28 & 25 & $0.79(0.39,1.63)$ & a \\
\hline$>1500$ Eth. Birr & 4 & 5 & $1.11(0.27,4.50)$ & a \\
\hline \multicolumn{5}{|l|}{ Cassava Consumption } \\
\hline Never Consume & 57 & 23 & 1 & 1 \\
\hline Consume & 7 & 43 & $15.22(5.98,8.74)^{* *}$ & $44.82(11.0,182.6)^{* *}$ \\
\hline
\end{tabular}


Table 4 Factors associated with goiter at primary school children in Dawro zone, southwest Ethiopia, 2017, $(n=652)$

\begin{tabular}{|c|c|c|c|c|}
\hline \multirow{2}{*}{$\begin{array}{l}\text { Variables with Category } \\
\text { Age of the children }\end{array}$} & \multicolumn{2}{|c|}{ 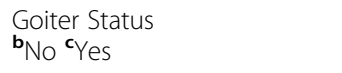 } & \multirow[t]{2}{*}{$\begin{array}{l}\text { Crude OR } \\
(95 \% \mathrm{Cl})\end{array}$} & \multirow[t]{2}{*}{$\begin{array}{l}\text { Adjusted OR } \\
(95 \% \mathrm{Cl})\end{array}$} \\
\hline & & & & \\
\hline 7-9years & 200 & 156 & 1 & 1 \\
\hline 10-12 years & 96 & 200 & $2.67(1.94,3.68)^{* *}$ & $2.23(1.32,3.77)^{*}$ \\
\hline \multicolumn{5}{|l|}{ Sex of the children } \\
\hline Male & 220 & 77 & 1 & 1 \\
\hline Female & 76 & 279 & $10.49(7.29,15.08)^{* *}$ & $9.20(5.30,15.97)^{* *}$ \\
\hline \multicolumn{5}{|l|}{ Family size } \\
\hline$<=5$ & 190 & 226 & 1 & a \\
\hline$>5$ & 106 & 130 & $0.85(0.75,1.42)$ & a \\
\hline \multicolumn{5}{|c|}{ Family educational status } \\
\hline No formal education & 154 & 231 & 1 & a \\
\hline Formal education & 142 & 125 & $0.59(0.43,0.80)^{* *}$ & a \\
\hline \multicolumn{5}{|l|}{ Geographic location } \\
\hline Lowland & 152 & 174 & 1 & a \\
\hline Highland & 144 & 182 & $1.10(0.81,1.50)$ & a \\
\hline \multicolumn{5}{|l|}{ Duration of stay in area } \\
\hline$<=1$ year & 6 & 16 & 1 & a \\
\hline$>1$ year & 290 & 340 & $0.44(0.17,1.14)$ & a \\
\hline \multicolumn{5}{|l|}{ Family monthly income } \\
\hline$<500$ Eth. Birr & 32 & 311 & 1 & 1 \\
\hline 500-1500 Eth. Birr & 200 & 35 & $0.02(0.01,0.03)^{* *}$ & $0.02(0.01,0.04)^{* *}$ \\
\hline$>1500$ Eth. Birr & 64 & 10 & $0.02(0.01,0.03)^{* *}$ & $0.02(0.01,0.04)^{* *}$ \\
\hline \multicolumn{5}{|l|}{ Cassava Consumption } \\
\hline Never consume & 139 & 150 & 1 & a \\
\hline Consume & 157 & 206 & $1.22(0.89,1.66)$ & a \\
\hline
\end{tabular}

*P.Value $<0.05{ }^{* *}$ P.Value $<0.001$

${ }^{a}$ Not appeared in the final model (not significant) when backward LR method used

${ }^{\mathrm{b}} \mathrm{No}=$ Goiter (neck swelling) not detected during thyroid gland examination

${ }^{\mathrm{C}}$ Yes $=$ Visible and/or palpable thyroid swelling was detected during thyroid gland examination

\section{Discussion}

According to $\mathrm{WHO} / \mathrm{UNICEF} / \mathrm{IGN}$, the median urinary iodine concentration in school children is a good indicator of the iodine status in the general population [32]. In this study the median UIC was $96.12 \mu \mathrm{g} / \mathrm{l}$. Even though this median UIC level was slightly below normal, more than half, 66 (50.8\%) of the children had UIC $<100 \mu \mathrm{g} / \mathrm{l}$. However; we cannot use this value to categorize iodine status of the study population, since UIC value of an individual child cannot be used to categorize iodine status in any population $[2,31,32]$.

The median UIC finding of this study $(96.12 \mu \mathrm{g} / \mathrm{l})$ was better than reports from south Ethiopia, Hawassa town $(1.9 \mu \mathrm{g} / \mathrm{l})$ [24] and Burie and Womberma district of west Gojam in Ethiopia ( $5 \mu \mathrm{g} / \mathrm{l})$ [23]. The differences could be related to efforts made by Ethiopian government and other partner's with regard to salt iodization, distribution, awareness creation of public through trained
HEWs which could have increased the demand for iodized salt utilization compared to the periods where other studies were conducted.

Prevalence of goiter is considered as a public health problem if it is equal to or greater than 5\% [2] and endemic if it exceeds $10 \%$ [32]. In this study setting, the prevalence of goiter was found to be $54.6 \%$, confirming that it is an endemic and severe public health problem. The finding was in line with the reported prevalence of Burie and Womberma district in Ethiopia (54.5\%) [23], but higher than the reports from northwest Ethiopia, Metekel zone (39.5\%) [26] and Dabat district (29.1\%) [11]. It is also higher than the reported prevalence from one of the districts of India (7.75\%) [5] and Nigeria (40.2\%) [10].

The high goiter prevalence in current study setting could be attributed partly to the mountainous and hilly nature of the area and high rainfall in most seasons of 
the year which might have resulted in leaching away iodine from top soil for long time. The other reason could be related to the time of study. Those studies conducted in other parts of Ethiopia and cited here [11, 26] were done after the implementation of USI program in the country in 2011. Therefore; the program implementation and enforcement might have contributed to the reduction of goiter prevalence in some accessible areas of the country.

As indicated above, there was discrepancy between median UIC $(96.12 \mu \mathrm{g} / \mathrm{l}$, nearly normal) and goiter prevalence $(54.6 \%$, high). The observed difference in this study may reflect the fact that goiter is an indicator of chronic ID. That is, some of the cases currently with normal iodine intake may be the old iodine deficient one who already developed it before but it takes long time for the thyroid enlargement to resolve and they are still living with goiter.

When we assess the iodine content of salt sample at household level, almost two-third (63.5\%) contains inadequate iodine. This result shows not the absence of iodized salt in the area rather the insufficiency of iodine in the salt. This could be due to loss of iodine under local conditions in the supply- chain management from time of iodization (production level) to time of distribution at consumer level. A study conducted in Ethiopia by Shawel D. et al. revealed $57 \%$ reduction of iodine concentration in the salt sample from the production site to the consumers (household level) [14]. However, the aim of this study was not to evaluate the loss of iodine and we invite further research in this area.

Goitrogenic food like cassava, cabbage, kale and sorghum were consumed with different frequency in current study area (Table 2), but only cassava consumption was significantly associated with UIC level in children. The possible explanation for this could be the presence of cyanogenic glycosides in these food groups other than cassava could be low and within the tolerable ranges. Those children who consume cassava were more likely to have low level of UIC than the non-consumer counter parts $(P<0.001)$. This was in line with similar studies conducted somewhere in Ethiopia [6, 13].

Goiter was more prevalent in female than male students $[\mathrm{AOR}=9.20 ; 95 \% \mathrm{CI}: 5.30,15.97]$ and about 2 times higher in children aged 9-12 years as compared to age group $7-9$ years $[\mathrm{AOR}=2.23 ; 95 \% \mathrm{CI}: 1.32$, 3.77]. Both results were in line with previous reports from Ethiopia $(9,25]$. As age increase in school children, the iodine demand increase in both sexes due to physical and physiological changes in the body. Females are more vulnerable than males due to early puberty, inhibitory effect of estrogen on iodine uptake and also its goitrogenic effect by increasing thyroid follicular proliferation [12].
Children of those families who gain higher income $(\geq 500$ Eth. Birr) per month were less likely develop goiter as compared to the lower income groups $(<500$ Eth. Birr) $[\mathrm{AOR}=$ 0.02; 95\% CI: 0.01, 0.04]. The odds of developing goiter among children from households with medium to high wealth status were lower as compared to children from poor (low income) households. This finding was supported by the recent studies done in Assosa town, west Ethiopia and Dabat district, northwest Ethiopia [6, 11]. The lower prevalence of goiter in households with higher wealth index could be related to household's food purchasing power and food security status. Rich family has better access of both iodized salt and variety food. This in turn improves the child's dietary diversity and prevents him from goiter.

Children with higher age group (10-12 years) were about 3.6 times more likely to have insufficient UIC level than the lower age groups (7-9 years), $[\mathrm{AOR}=3.57 ; 95 \%$ CI: 1.33, 9.62]. As age increases the iodine requirement also increased in this age group to support rapid growth (pubertal growth spurt). Moreover; this age is the period of early adolescence where iodine requirement increased due to physiological and hormonal changes. To compensate this requirement the body utilizes more iodine as supported by several studies [9, 17, 23].

Even though, UIC level was significantly associated with students sex in bivariate analysis, it was not significant during multivariable logistic regression analysis. In previous studies UIC level was significantly associated with sex, Ethiopia [25] and Nigeria [18]. The discrepancy could be attributed to the small sub-sample size of UIC $(n=130)$.

Children living in highland area were less likely to have sufficient UIC level than their counter parts in lowland. This could be attributed to the fact that highland area is more mountainous and characterized by high rainfall than the low one. This leads to erosion and leaching away of iodine from top soil. Consequently; crops grown in such area can't provide sufficient iodine when consumed leading to low level of UIC $[2,13,20]$.

There was significant association between cassava consumption and the levels of UIC. Children who consume cassava were more likely to have low level UIC relative to the non-consumer ones $[\mathrm{AOR}=44.82,95 \% \mathrm{CI},(11.00$, 182.61). Here, the wider confidence interval could be a reflection of smaller sub-sample of UIC. Similar result was observed in recent study conducted by Gabriel M, et al., 2014 in Nairobi, Kenya [19].

It is well known that consumption of cassava (including the frequency and duration of consumption) has been shown as a risk factor for goiter development among children [20]. However; in this study there was no association between cassava consumption and goiter. This could be related to the time of introduction of cassava. It is well known that goiter is the long term 
consequence of iodine deficiency but cassava was introduced to Dawro zone more recently and propagated to lowland kebeles around Omo River bordering Wolaita zone.

\section{Strength and limitation of the study}

Both school and community-based recruitment strategies were used with multiple indicators (UIC, goiter grade, salt iodine content and interview) to measure the prevalence of IDD in the study population. Despite the strength, this study is not free of limitations. One of the limitations was the method used to test the salt samples. We tested salt samples using iodine rapid test kit which shows only the presence or absence of iodine in the salt (qualitative). If Iodometric titration test was done, it would have estimated the iodine content of the salt samples quantitatively. But, we believe this does not affect our finding and conclusions related to the objective of the study, because our primary aim was not to evaluate the iodine content of the salt.

The other limitation was both urine and salt samples were collected from sub-samples, due to resource shortage. However; the sample size of the sub-samples is still fairly sufficient to estimate the prevalence of IDD in the study population. The last limitation to be acknowledged could be the nature of the study design (cross-sectional). In this type of study, it is hard to explain the causal relationship between IDD and its predictors, rather the finding alerts one to conduct further research using more controlled methods to identify causal relationship and to appreciate whether the salt is not iodized at site of production or due to post-production losses at different levels of supply-chain.

\section{Conclusion}

In this study, the median UIC was $96.12 \mu \mathrm{g} / \mathrm{l}$ which is close to the WHO recommended cut-off $100 \mu \mathrm{g} / \mathrm{L}$. When we observe the UIC values for the individual children, $66(50.8 \%)$ of the children had inadequate iodine intake (UIC < $100 \mu \mathrm{g} / \mathrm{l}$ ). However; UIC cannot be used to categorize iodine status in an individual. Therefore, based on a median UIC $(96.12 \mu \mathrm{g} / \mathrm{l})$, the study population is mildly iodine deficient. In addition, there was low concentration of iodine in the salt, high consumption of cassava (goitrogenic) and high prevalence of goiter indicating the presence of severe chronic iodine deficiency and the potential risk in the area. Based on these findings, intensifying efforts in the IDD elimination activities like iodized salt quality control, iodine supplementation for more vulnerable groups and teaching community on techniques of cassava processing (to remove cyanide) for household consumption is highly recommended.

\section{Abbreviations}

EDHS: Ethiopian demographic and Health Survey; HEWs: Health extension workers; IDD: Iodine deficiency disorder; IGN: lodine global network; IQ: Intelligence quotient; PPM: Parts per million; SAC: School age children; SNNPR: Southern Nation Nationalities and People region; UIC: Urinary iodine concentration; UNICEF: United Nations children's fund; USI: Universal salt iodization; WHO: World health organization

\section{Acknowledgements}

The authors would like to thank the study subjects, data collectors and supervisor without their willingness and participation this study could not be achieved. Our special thanks goes to Jimma University, Wolkite University and Dawro zone administration and health departments for their continuous support and encouragement.

\section{Authors' contributions}

A. A conceived and designed the study, performed the analysis and interpretation of the data, and drafted the manuscript. B.T participated in the study design, analysis and manuscript revision. Both authors read and approved the final manuscript.

\section{Funding}

This research was funded by Jimma University (Ref. No- RPGC/4052/2008).

The funder had no role in the design, data collection, analysis, and interpretation of this study.

\section{Availability of data and materials}

All data used and/or analyzed during the current study are available from the corresponding author on reasonable request.

\section{Ethics approval and consent to participate}

Ethical clearance and approval was obtained from Jimma University after being reviewed by the institutional review board (IRB). Official letter of cooperation was written by the University to the study area administrative office. The office in turn wrote a letter of cooperation to the respective school directors. Verbal consent was obtained from the parents or guardians of each pupil after the school director and parents committee discussed on the proposal. Assent was also obtained from pupils. Written consent was not necessary at least for three reasons: first, the research protocol was neither hostile nor invasive to the study participants. Second, according to the legislative of research ethics in Jimma University, having verbal consent is enough for non-invasive research procedures. Third, as the majority of parents/guardians cannot read and write, getting written consent may be difficult. Moreover, all the study participants/guardians were informed about the purpose and confidentiality of the information along with their right to refuse. In cases of clinical examination of goiter, any child diagnosed with goiter (his/her parent) was advised to visit the nearby health facility to obtain possible advice and management.

\section{Consent for publication}

Not applicable.

\section{Competing interests}

The authors declare that they have no competing interests.

\section{Author details}

${ }^{1}$ Department of Public Health, College of Medicine and Health Sciences, Wolkite University, P.O.Box: 07, Gubre, Ethiopia. ${ }^{2}$ Department of Nutrition and Dietetics, College of Public Health and Medical Sciences, Jimma University, P.O.Box: 378, Jimma, Ethiopia.

Received: 6 August 2019 Accepted: 20 March 2020

Published online: 08 June 2020

\section{References}

1. Ahad F, Ganie SA. lodine, lodine metabolism and lodine deficiency disorders revisited. Indian J Endocr Metab 2010; 14:13-17. Available from: http://www.jjem.in/text.asp?2010/14/ 1/13/75080.

2. WHO. Assessment of iodine deficiency disorders and monitoring their elimination: A guide for program managers. 3rd ed. Geneva: World Health Organization; 2007. p. 6-54. Google Scholar. 
3. UNICEF Regional Office for South Asia. Iodine Deficiency Disorders and Universal Salt lodization: A South Asia Priority. Report of a Regional Consultation (published), Nepal, May 2002. https://www.unicef.org/rosa/ lodine.pdf. Date Accessed 8 Mar 2016.

4. Egbi G. Prevalence of vitamin a, zinc, iodine deficiency and Anemia among 2-10 year- old Ghanaian children. AJFAND. 2012:12(2):5946-58.

5. Kapil U. (2010). Successful efforts toward elimination of iodine deficiency disorders in India. Indian J Community Med 2012; 35:455-468.

6. Rawal SV, Kedia G. A Prevalence Study of lodine Deficiency Disorder in children of primary schools in Gandhinagar district, India. Natl J Comm Med. 2011;2(3):478-82.

7. Gebriel TW, Assegid S, Assefa H. Cross-sectional Survey of Goiter Prevalence and Household Salt lodization Levels in Assosa Town, Beni Shangul-Gumuz Region, West Ethiopia. J Preg Child Health. 2014;1:119 Google Scholar.

8. Ivanova L. lodine deficiency disorders and salt iodisation: public health implications. J Nutr Health Food Eng. 2015;2(1):1-2.

9. Berhanu N, Michael KW, Bezabih M. Endemic goiter in School Children in Southwestern Ethiopia. Ethiop J Health Dev. 2004;18(3):175-8.

10. Sanusi, Ekerette. Nutrition and goiter status of primary school children in Ibadan, Nigeria. African J Biomed Res. 2009;12(1):37-41.

11. Zegeye A, Ejigu G, Amare T. Poor dietary diversity, wealth status and use of un-iodized salt are associated with goiter among school children: a crosssectional study in Ethiopia. BMC Public Health. 2017;17:44. https://doi.org/ 10.1186/s12889-016-3914.

12. Darnton-Hill I, Webb P, Harvey PWJ, Hunt JM, Dalmiya N, Chopra M, Ball MJ, Bloem MW, de Benoist B. Micronutrient deficiencies and gender: social and economic costs. Am J Clin Nutr. 2005;81:1198-205.

13. Abuye $C$, Berhane $Y$, Ersumo $T$. The role of changing diet and altitude on goitre prevalence in 5 regional states in Ethiopia. East Afr. J.Public Health. 2008;5(3):163-8.

14. Shawel D, Hagos S, Lachat CK, Kimanya ME, Kolsteren P. Post-production losses in iodine concentration of salt hamper the control of iodine deficiency disorders: a case study in northern Ethiopia. J Health Popul Nutr. 2010;28(3):238-44.

15. Andersson M, Karumbunathan V, Zimmermann MB. Global iodine status in 2011 and trends over the past decade. J Nutr. 2012;142(4):744-50.

16. Elizabeth N. Pearce, Maria Andersson, Michael B. Zimmermann. Global lodine Nutrition: where do we stand in 2013? Zurich, Switzerland. Thyroid; 2013, 23(5): Found at: http://www.ign.org/cm_data/2013_Pearce_Global_ iodine_nutritionWhere_do_we_stand_in2013_Thyroid.pdf. Date Accessed 21 Nov 2017.

17. Francesco Branca, Jonas Vollmer, Jessica, Michael Zimmerman. Eliminating iodine deficiency disorders by 2020. Zurich, Switzerland. 26 May 2017. Available at: https://www.gainhealth.org/knowledge-centre/towardelimination-iodine-deficiency-disorders-2020/ D. Accessed on 25, Oct 2017

18. Nwamarah, Joy Ugo and Okeke, Elizabeth Chinwe. A pilot study of iodine and anthropo- metric status of primary school children in Obukpa, a rural Nigerian community. J Public Health Epidemiol 2012; 4(9), 246-252.

19. Gabriel M. Kishoyian, Eliud N. M. Njagi, George O. Orinda, Joseph N. Ngeranwa, Joash Auka. Prevalence of lodine Deficiency Disorders and Urinary lodine Excretion among Primary School Children in Makina and Kilimani in Nairobi, Kenya. IJIRD. 2014; 3(4), 199-203.

20. Abuye C, Berhane $Y$. The goitre rate, its association with reproductive failure, and the knowledge of iodine deficiency disorders (IDD) among women in Ethiopia: Cross-sectional community based study. BMC Public Health. 2007; 7:316. doi:https://doi.org/10.1186/1471-2458-7-316. Found online at: http:// www.biomedcentral.com/1471-2458/7/316. Accessed 13, Feb 2016.

21. Iodine Global Network. Global Scorecard of lodine Nutrition in 2017 in the general population and in pregnant women (PW). IGN: Zurich, Switzerland. 2017. Available at: http://www.ign.org/cm_data/IGN_Global_Scorecard_ AllPop_and_PW_May2017.pdf. Accessed 25 Oct 2017.

22. Ambaye TG. Knowledge of iodine deficiency disorders and intake of iodized salt in residents of Mekelle Tigray, Ethiopia. J Food Sci Nutr Ther. 2015;1 (1): 002-7.

23. Aweke KA, Adamu BT, Girmay AM, Yohannes T, Alemnesh Z. And C Abuye. lodine deficiency disorders (idd) in Burie and Womberma districts, west Gojjam, Ethiopia. AJFAND. 2014;14(4):9170-8.

24. Girma M, Loha E, Bogale A, Teyikie N, Abuye C, Stoecker BJ. lodine deficiency in primary school children and knowledge of iodine deficiency and iodized salt among caretakers in Hawassa town: southern Ethiopia Ethiop.J Health Dev. 2012;26(1):30-5.
25. Hailu S, Wubshet M, Woldie H, Tariku A. lodine deficiency and associated factors among school children: a cross-sectional study in Ethiopia. Belgian Public Health Assoc. 2016;74(46):1-13.

26. Girma K, Nibret $\mathrm{E}$, Gedefaw $\mathrm{M}$. The status of iodine nutrition and iodine deficiency disorders among school children in Metekel zone, Northwest Ethiopia. Eth J Health sci. 2014;24(2):109-16.

27. Gebremariam HG, Yesuf ME, Koye DN. Availability of Adequately lodized Salt at Household Level and Associated Factors in Gondar Town, Northwest Ethiopia. Hindawi Publishing Corporation. 2013;2013:1-6 Google Scholar

28. Lijalem T, Zereu G, Tebeje M. Opportunities and constraints of beekeeping in Wolaita and Dawro zones, southern Ethiopia. Afr J Agric Res. 2017;12(18): 1587-92.

29. CSA. Summary and Statistical Report of the 2007 Population and Housing Census Results. 2007; Federal Democratic Republic of Ethiopia: population census commission. Central Statistic Agency of Ethiopia.

30. Charlton KE, Ware LJ, Baumgartner J, Cockeran M, Schutte AE, Naidoo N, Kowal P. lodine Status Assessment in South African Adults According to Spot Urinary lodine Concentrations, Prediction Equations, and Measured 24h lodine Excretion. Nutrients. 2018;10:736. https://doi.org/10.3390/ nu10060736.

31. WHO. Indicators for assessing lodine deficiency disorders and their control through salt iodination.1994;WHO/NUT/94.6:1-35.http://apps.who.int/iris/ bitstream/10665/70715/1/ WHO_NUT_94.6.pdf. Date Accessed 1 Jan.2016.

32. WHO. Urinary iodine concentrations for determining iodine status deficiency in populations. Vitamin and Mineral Nutrition Information System. Geneva: World Health Organization. 2013; (http://www.who.int/ nutrition/vmnis/indicators/urinaryiodine. Accessed 20 Mar 2017.

\section{Publisher's Note}

Springer Nature remains neutral with regard to jurisdictional claims in published maps and institutional affiliations.

Ready to submit your research? Choose BMC and benefit from:

- fast, convenient online submission

- thorough peer review by experienced researchers in your field

- rapid publication on acceptance

- support for research data, including large and complex data types

- gold Open Access which fosters wider collaboration and increased citations

- maximum visibility for your research: over $100 \mathrm{M}$ website views per year

At BMC, research is always in progress.

Learn more biomedcentral.com/submissions 